\title{
Developing qualitative coding frameworks for educational research: immigration, education and the Children Crossing Borders project
}

\section{Jennifer Keys Adair \& Giulia Pastori}

To cite this article: Jennifer Keys Adair \& Giulia Pastori (2011) Developing qualitative coding frameworks for educational research: immigration, education and the Children Crossing Borders project, International Journal of Research \& Method in Education, 34:1, 31-47, DOI: 10.1080/1743727X.2011.552310

To link to this article: http://dx.doi.org/10.1080/1743727X.2011.552310

曲 Published online: 20 Apr 2011.

Submit your article to this journal

Џll Article views: 871

View related articles $\sqsubset$

Citing articles: 2 View citing articles $\square$ 


\title{
Developing qualitative coding frameworks for educational research: immigration, education and the Children Crossing Borders project
}

\author{
Jennifer Keys Adair ${ }^{\mathrm{a} *}$ and Giulia Pastori ${ }^{\mathrm{b}}$ \\ ${ }^{a}$ Department of Curriculum and Instruction, University of Texas at Austin, 1 University \\ Station, Mailcode D5700, Austin, TX 78712, USA, ${ }^{b}$ Faculty of Humanities and Educational \\ Sciences, State University of Milan-Bicocca, Milano, Italy
}

(Received 12 April 2010; final version received 31 July 2010)

\begin{abstract}
The Children Crossing Borders (CCB) study is a polyvocal, multi-sited project on immigration and early childhood education and care in five countries: Italy, Germany, France, England and the USA. The complicated nature of the data pushed us as a group to expand our methodological resources to not only organize the data but also to make it searchable, and thus comparable, so that we could understand more deeply the perspectives and desires of immigrant parents and preschool teachers on education. This article uses examples from the CCB project to show how coding frameworks can be created to support large-scale collaborative projects that seek to amplify the voices of marginalized groups in educational qualitative research. We argue here that creating qualitative coding frameworks depends on a balance between etic/insider and emic/outsider knowledge, decisions about interpretation and practical compromises about labels and meanings. These three elements play out in necessary debates and disagreements as part of the creative process and are critical for large-scale projects looking for a coding framework and a coding process that is both useful and meaningful.
\end{abstract}

Keywords: international comparative research; ethnography; qualitative methods

The Children Crossing Borders (CCB) study $^{1}$ is a polyvocal, multi-sited project on immigration and early childhood education and care in five countries: Italy, Germany, France, England and the USA. The research data in CCB comprised mainly of focus group interviews with immigrant parents and preschool teachers in multiple cities within each country. The resulting data set includes over 150 focus group interviews in multiple languages including the dominant languages in each country as well as Arabic, Spanish, Turkish, Punjabi, Somali, Mandika and Mixtec. The complicated nature of the data pushed us as a group to expand our methodological resources to not only organize the data but also to make it searchable, and thus comparable, so that we could understand more deeply the perspectives and desires of immigrant parents and preschool teachers on early childhood education and care in five countries.

Despite scepticism by the ethnographically informed research teams, coding became a first, but cautiously taken analytical step that resulted in important

*Corresponding author. Email: jenniferadair@mail.utexas.edu 
conversations and discussions early on in the data collection process. Within qualitative work, especially anthropological endeavours, coding is usually enacted as an organizational tool, rather than as an analytical, findings-oriented mechanism. Coding software has improved dramatically since its inception and the actual process of entering data and applying codes is now a relatively quick process. The ease of using coding software can be misleading because creating a coding framework and making decisions about the role of coding in a project still necessitates a great deal of conversation and debate. There are qualitative research explanations of using coding software and how to apply more sophisticated analytical tools with the software (Strauss and Corbin 1998; Auerbach and Silverstein 2003). Creating a coding framework - a list of organizational codes and subcodes - was the richest and most time-consuming part of coding and is the focus of our discussion here. This article uses examples from the CCB project to show how coding frameworks can be created to support large-scale collaborative projects that seek to amplify the voices of marginalized groups in educational qualitative research. We argue here that creating qualitative coding frameworks depends on a balance between etic/ outsider and emic/insider knowledge, decisions about interpretation and practical compromises about labels and meanings. These balances represent a 'never-ending' challenge especially in a multi-cultural and multi-language research teams and in diverse research contexts.

\section{Coding within the video-cued ethnographic research design}

The CCB project methodology is based on video-cued ethnography as used by Tobin, Wu, and Davidson in Preschool in three cultures (1989) and again recently in Preschool in three cultures revisited (Tobin, Hsueh, and Karasawa 2009). Video-cued methodology was first used by Margaret Mead and George Bateson (1954) and then George and Louise Spindler when they made films not for data but for stimulating discussion and pointing out the presence of culture. In Mead's famous films about childrearing (see 1954s Bathing Babies for an example), she points out that when Americans watch Japanese childrearing practices like cobathing they are not so much thinking about this Japanese cultural value but how it translates or compares to American childrearing practices that typically (but not always) frown on children and parents bathing together. In this regard, the films she made were to create discussion about culture by creating a comparison. The films were not the data but were used to study the conversations that resulted from watching them because the conversations reveal the cultural differences among those who saw the films.

Similarly, each CCB research team collecting data in Germany, France, Italy, England and the USA made a film of a preschool that serves children of immigrants. The preschool in each country was to exemplify typical practices of that country so that when teachers, parents and administrators watched the films, they would recognize and be familiar with most of what they saw. Teachers, parents and administrators watched the films from their own country and discussed what they liked and did not like as well as how the filmed preschool was similar and/or different from their own. Within each country, we conducted interviews with groups of parents and groups of practitioners in at least five diverse cities per country and used the films to stimulate discussions about what immigrant parents and preschool practitioners believe immigrant children should be doing in their early schooling years. The 
primary goal of the project is to give voice to the hopes, beliefs and concerns of immigrant parents about the education and care of their young children and then to compare these ideas with those of the preschool teachers who work with their children. Focus groups of immigrant parents and preschool teachers watched the film from their own country as well as 1-2 films from the other countries in the project. Reacting to specific scenes such as young children speaking their home language at school or children fighting over toys or immigrant parents and teachers interacting at school prompted reactions from our informants about important issues facing early childhood education and care in the USA and Europe including parent/teacher interactions, pedagogy, multilingual children and the presence of immigrants in early childhood education and care centres. CCB's size and scope made the research objective to hear and take seriously the voices of immigrant parents and preschool teachers within the comparative analysis challenging and complicated.

When coding software was first introduced to the CCB group as a way to organize and search the data, there was a great deal of scepticism. This scepticism stemmed from an analytic framework that included close, interpretative readings of the transcripts. We had already designed a Bakhtin-informed analysis (Bakhtin and Holquist 1981; Bakhtin, Holquist, and Liapunov 1990) that prescribed looking closely at texts for subtlety, contradictions, metaphors, redundancy and emotion. This interpretive analysis would allow us to find deeper meanings in the transcripts and avoid treating informants' words as having self-evident meanings (as if interviewees always mean what they say and say what they mean). We planned to read the transcripts both critically and generously and to construct multiple possible interpretations of what our informants were saying to each other and to us (Tobin 2000). We were interested in the informants as experts, relying on their own sense of logic to make sense of immigration and early schooling experiences. These ideals - listening to the voices of teachers and parents and resisting self-evident meanings of their words - seem at odds with a coding analytic process that takes one or two possible meanings and assigns those meanings as labels or codes to them. We collectively worried that coding software would disembody us from our interpretative instinct by forcing us to categorize with narrowly defined codes and to do it before we really understood the data.

For the remainder of this discussion, we will focus on the challenge of balancing the process of creating a coding framework with the voices of informants and the key topics of a research design. And then discuss the theoretical complications of using a coding framework within a collaborative, qualitative analytic design. We begin with the challenge of creating a coding framework that is representational of the research design and objectives as well as the data from informants.

\section{Diverse avenues to immigration and early childhood education}

Trying to understand the impact of immigration on early childhood education and care through the perspectives of immigrant parents and preschool teachers meant a focus on the intersectionality of immigrant families and early childhood care centres. Developing a coding framework requires an ability to map out the ways in which parents and teachers talk about this intersection. In the CCB data set, immigrant parents and early childhood practitioners approached the intersection of immigration and ECE in a number of ways. Let's begin by hearing four ways of talking about immigration in connection with early childhood from two teachers and two immigrant parents. Sharon, the first teacher, works in a small town in the middle of the USA that has only 
recently received many new immigrant families from Mexico and Central America. She is a White teacher who was born in the USA. Her 10 years of experience have all been in preschool classrooms. When we asked her about the immigrant families at her school and why she was concerned for the education achievement of children of immigrants, she told us about immigration policies in her town. She described why children in her classroom would sometimes stop coming to school.

You'll get into that rumor of Meat $\mathrm{Co}^{2}$ is shutting down or immigration is coming, or you know, it's all the - it's gossip is what I would call it. I think a lot of times when that happens, then a lot of families will leave.

Sharon argues that immigration policies like immigration raids push families, including children in her class, to leave the town. The decision to focus her comments on policy rather than other aspects of immigration suggests a deep concern about how immigration policy is affecting her students and her own work as a teacher. In this comment, she approaches immigration through policy, legality, immigrant parent labour and the role of being a teacher.

The second teacher, Antonia, works in a public preschool located in a workingclass neighborhood of Milan, Italy. She has over 15 years of teaching experience. When the interviewer asks how the immigrant community is integrating within the city, she recounts a conversation between her and another teacher about whether Chinese immigrant families want to be touched. When she tells the story - she offers her own somewhat problematic cultural interpretation of Chinese immigrants in Italy.

I was talking the other day with a teacher who worked in a middle school. She was telling me precisely that she works a lot with Chinese students. And why don't the Chinese people want to be touched? Because they say that we stink. I mean, they, that's the problem. She encountered a lot of difficulties in her relationships with Chinese students, that when they learned Italian, I mean, she explained to them the reason for it. I mean, we feel like they stink, because they smell like garlic, we also stink. It's a reciprocal thing, so because of that, they don't want physical contact. In fact, she was left speechless. Those are things we don't know, for example, why don't they want to be touched? It's actually true. If we don't smell ourselves, we stink. We're Italian and we're used to it, obviously.

Antonia talks about immigration in terms of a specific immigrant community and their aversion towards an aspect of Italian life. Her response to her teacher-colleague seems to be an attempt to explain mutual disgust with smell between immigrant and native-born communities. Antonia talks about immigration in terms of groups having a difficult time with one another and centres her comments on the interactions between immigrant and native-born communities, stereotypes, taste and cultural traits. Antonia also gives us an example of how people outside early childhood education might be talking about immigrant groups.

So far, we can approach the intersection of preschool and early childhood education through policy, labour and the role of a teacher as well as through the relationship between the native-born or dominant culture and the immigrant community. When we look to the perspectives of immigrant parents, we see even more avenues to immigration and early childhood education. Mercedes, a mother of two, was born in Mexico and is now living in the USA. Her son was in preschool at the time. When the interviewer asked her about her experience so far in the USA, she recounted this story. 
We just came to United States. I was standing, probably by three months or second from my country. I went to the hospital. I can't speak the language. I was sitting in the hospital for whole day waiting so they could find somebody to speak Spanish.

Mercedes brought up language issues and how institutions welcome or reject immigrant groups. She shared a personal experience in an institutional setting. She approached immigration and preschool from the perspective of institutions and discrimination she endures during routine parental activities.

Dahlia, a Moroccan born mother living in Italy, was asked about how her life was as an immigrant parent. She described her experience trying to pass on the cultural and linguistic knowledge from her home country to her son who was born in Italy. The son she refers to here is four years old.

I don't know, it's not that I forgot my country, that's impossible. My origins, that's impossible. It's just that my son who lives here (.), I lived there until I was nineteen years old basically nineteen, I know everything about my country. I know what Islam means, what Muslim means, what Moroccan means, really. So I always say: 'You are Tunisian, Arab (.)', because I'm Moroccan, his father is Tunisian, so he's Tunisian. The important thing is Arab; he knows what the word Arab means. But the fact that you live here is another thing, because we came here for certain reasons; another reason is that I met his father here, because I didn't know him, really.

Dahlia offers yet another entrance into immigration and early childhood education. She addresses the identity issues she faces in being Moroccan and trying to pass on that identity along with a Tunisian identity from her husband to a son who is being raised in Italy. Dahlia's focus on identity and multicultural/multilingual characteristics within immigrant communities is yet another way to talk about immigration and early childhood education.

Collectively, these immigrant mothers and early childhood practitioners approached immigration and early childhood education through policy, identity, relationships between host and immigrant communities and institutions. These four approaches to the intersection of immigration and early childhood education represent many of the parents and teachers in the CCB research. The teachers and mothers in the above example illustrate the difficulty of creating a framework. Focusing on what teachers and parents say about the intersection of preschool and early childhood education is important to representing their voices as closely and sincerely as possible. But often a coding framework needs to be created before all of the data is collected and often, the coding framework is essential to beginning any large-scale comparative process. Essentially this means taking a step in analysis by categorizing the words of informants but doing so without understanding the full scope and logic of their words. How can large-scale educational research projects create a set of codes that represent the voices of informants even while keeping to practical timelines for data collection and analysis?

\section{Posturing within emic/etic and $a$ priori/a posteriori}

Coding acts like a created logic to organize and arrange data, the coding framework being the blueprint of that logic. One of the main challenges to any qualitative project guided theoretically by an emphasis on the voices of informants is creating a coding framework that represents an emic perspective rather than a purely etic construction. 
This challenge was complicated within the CCB study because the project had a large amount of data and the coding framework had to be sensible to researchers from five countries. Large qualitative projects within education face similar quandaries - needing to enter into the analytic phase by creating a coding framework before data collection was completed.

We discovered as a project that lengthy conversations are necessary to developing a coding framework that sustains rather than blocks a qualitative inquiry and that these conversations are helpful if they first balance two sets of knowledge binaries borrowed from the fields of philosophy and anthropology: Emic/Etic and A priori/A posteriori. Emic/Etic, in anthropology are terms associated with cultural descriptions of ideas, materials, beliefs and behaviours (Geertz 1973; Erickson and Murphy 2008). Emic descriptions are meaningful to insiders within a cultural group and are based within a logic cultural members share. Etic descriptions are meant to be transferable between cultural groups and represent usually the logic of the outsider or the researcher in an effort to make the insider logic visible and understandable to outsiders (Headland, Pike, and Harris 1990).

Beginning with an etic structure, the guiding research questions and research objectives act like a starting point. In the CCB process, we began with categories that represented our areas of inquiry. This construction was an a posteriori process that brought together the areas of inquiry at the heart of our research. Then, we moved to an a posteriori process that included close readings of a sample and diverse group of transcripts to try and get an idea of how parents and practitioners conceptualized the areas of inquiry. A priori/A posteriori is a traditional distinction of two processes of knowledge that focus on the position of the knowledge in relation to experience. A priori knowledge is independent of experience or is knowledge that somehow is accepted without additional proof or evidence and a posteriori knowledge comes from experience or is rooted in its validity because of experience/evidence. We used these categories like weights on a balance, helping us create a system that could hold our research questions and important topics as well as the specific and unexpected ways parents and teachers talked about them.

As we showed earlier, immigration was a particularly challenging topic for us to code. Our coding of immigration began with a priori categories stemming from our research questions about immigration and early childhood education and our etic ideas based on our disciplines and backgrounds. These were structured by emic understandings of how our informants talked about immigration and a posteriori categories (or versions) of immigration our informants concentrated on. For example, many of the immigrant parents and early childhood practitioners talked about immigration as not belonging to the dominant group or the act of trying to be successful within the dominant group or national citizenry. This became a way to organize the data under the topic of immigration because this was a main way the informants spoke about immigration.

By looking closely at a sample of the data, we saw that emic descriptions of immigration did not include facts or statistics but rather personal experiences, experiences of family members, metaphors and concerns. We began drafting code names that captured their emic avenues into immigration. Transcript excerpts like the Italian teachers' comments about Chinese and Italian mutual beliefs about how bad each smells were coded as 'public discourse' under the topic of immigration. The logic behind having a code called 'public discourse' under the area of immigration was because many parents and teachers responded to the children of immigrants in the 
filmed classrooms by telling us that they hear comments about immigration from their friends, neighbours or out in the community. Their references to public ideas about immigration helped us understand the larger environment they operated within and also to trace how public ideas about immigration affected how parents and teachers acted in early childhood settings. This balance was not just a practical one but goes to the heart of our analytical design to hear the voices of immigrant parents and early childhood practitioners. Because we had to constantly check our framework of codes against the voices of our informants to make sure we were 'catching' their approaches to the main areas of inquiry like immigration as well as to other key areas like pedagogy, parent/teacher interactions and identity. This balancing act between etic and emic knowledge and a posteriori and a priori processes is what creates the coding framework, or blueprint, for a meaningful and useful coding process.

We anticipated the kind of data we would get from immigrant parents and early childhood practitioners but we were not sure exactly what aspects of our important topics they would concentrate on. Understanding the range of topics/codes and subcodes to fit a research question and a data set has been a key element of our theoretical discussions about coding. Being able to follow the logic of the coding framework, especially the names and organization of the codes and subcodes, is critical to using the framework to search and compare data. This process of developing a logic that balances emic and etic perspectives resulted in a blueprint of codes and subcodes that narrowed down each of the main topics we began with in our study. In each topic or code, we settled on subcodes that represented how our informants focused their discussion of each topic. For the topic of immigration, we organizationally have the topical code of immigration. And within the code of immigration are seven sub-codes:

Public discourse (about immigration)

- Neighborhood characteristics

- Migration stories

- Home country

- Discourse about racism

- Transformation - change (as a result of being in new country)

- Conflict with minorities

- Relationships to dominant

These subcodes only represent a tiny fraction of the possible ways people might talk about immigration but they are the ways our informants seemed to approach immigration most often.

At the very beginning of the coding process each country team listed a set of codes and subcodes to share with the group; however, these first discussions about coding failed and required a re-conceptualization of the entire process. We progressively had to recognize that when codes are intended to be based on before and after knowledge of the data and between etic and emic perspectives, entrance into the data and specific theoretical conversations need to happen before codes can be created and debated. Settling on codes became first a collaborative matter of brainstorming then a circular process of testing them against the data collected in five countries. Testing the data meant an ongoing debate about the scope and perspective of chosen codes, adjusting and/or rearranging the coding framework and then testing them again. 
To test the ability of the framework to search and retrieve the kinds of information we wanted, we used sample questions and practiced using the framework. For example, we tested whether the framework could answer questions like 'How do teachers collectively describe children of immigrants in their classrooms?' or 'What differences exist between immigrant parents' and teachers' ideas about good curriculum?' If we could not use the coding framework to search for the right data to answer these and other questions, we knew that we needed to add or clarify codes. This testing and retesting process produced more and more conversation and debate until we had created a logic that we all understood and that represented the data we had. When we found that our codes were too specific or not specific enough we would return to the data to clarify what the code name should be. If the coding framework remained confusing then we all went back to the data and conducted more close readings of the focus groups already conducted. In these types of cases when the framework could not answer questions or did not fit the data closely enough, it is most likely because we realized that the codes were too focused on the etic knowledge of the researchers and lacked representational quality.

\section{Diverse researchers within the coding framework process}

Besides the practical and theoretical balancing act between a project's areas of inquiry and the ways participants conceptualize those areas of inquiry, creating a coding framework has a third component which is the diverse input of researchers. Constructing a coding framework is an exercise in balancing power and perspective among the researchers themselves because it is a first analytical step.

Because a qualitative coding framework is a complicated balance of etic and emic perspectives as well as a process that represents powerful experiences, coding should never be an individual or isolated activity. Coding is a process of organization but also representation especially in a large-scale collaborative study. Who is creating the coding is important. Often in collaborative qualitative projects, researchers can be from different countries with different native languages, be at different stages in their academic careers and have different theoretical and methodological backgrounds. As Harkness et al. (2006) demonstrate, international collaborative research teams that utilize qualitative coding frameworks push researchers not only to understand the multiple languages, groups and contexts of the research data but also the perspectives of fellow researchers.

The international CCB team collectively, nationally and individually approached the data with a rather broad set of theories that included third-world feminism, sociocultural theory, globalization, critical race theory, post-structural theory and national traditions of educational theories and child development. While we were and still are individually informed by a large body of theoretical work, our efforts to create a coding framework represented a collaborative compromize that focused on international comparison, rather than individual or national agendas.

As a sub-group of the larger project directed to develop the coding framework, we were ourselves a diverse set of researchers. We represented each of the five countries as well as a number of native languages, methodological backgrounds in psychology, human development, sociology, pedagogy and anthropology and qualitative research experience. All of us had backgrounds in early childhood education and some level of qualitative research experience and we were a mix of doctoral students and senior scholar-researchers. We arrived at the task, used to talking naturally about schooling 
and immigration in certain ways and then were forced to confront the relativity of our own ideas as researchers.

The differences among researchers were substantive during the coding framework process and throughout the entire CCB project. Within the coding process, two areas of difference shaped the level of interpretation our coding framework enacted and the code names we used in our framework: the theoretical positions of the researchers and the national cultures around schooling. In the following two sections, we outline how these differences made an impact on how we coded the participants' words. First, we will discuss how theoretical differences, in this case around racism and equity, affected the level of interpretation we allowed for our coding framework. Then, we will demonstrate how national ideas about teaching and learning created problems when trying to agree on specific codes. These two examples are some of many examples of how challenging but important multiple perspectives can be within large-scale and/or international projects.

\section{Coding and interpretation}

What level of analysis or interpretation a coding framework represents is up to those who are creating it. This became particularly clear during a sensitive discussion about Claudia, an immigrant mother from Mexico living in a southwest city in the USA. After speaking highly of the early childhood programme her daughter attended, the interviewer asked her if there were other places she felt comfortable as an immigrant parent. She responded with the following difficult experience at a grocery store with her preschool age daughter.

I was buying groceries, and a woman told me, 'what are you doing here? This store is not for you, do you have one of these.' And she showed me a license? And she said, if you don't have one like this, you don't have any right to buy here. Go away! This time I was with my son, but he was older. He was scared saying, 'what is that woman yelling, mom?' I didn't say anything back to that woman; she was just saying things to me. In the store, nobody said anything to me, not even the manager in the store. I knew the store manager could have talked to her, asked her to calm down but he didn't say anything. Nobody did anything and the lady kept yelling.

The US researcher on the coding team, who was a graduate student studying racial discrimination in schooling, saw this story as an example of racism. The mother was verbally attacked because of how she looked and the ill-conceived, even hateful, ideologies that the women had of her. She embodied the immigration debate in the USA and showcased how racist ideas translate into difficult experiences for immigrant parents (Valdes 1996). From the USA researcher perspective, this story and similar ones necessitated a code called 'racism' to label similar harsh experiences immigrant parents encounter. She used critical race theory to make sense of why such a situation would be allowed to happen where a young mother would be verbally attacked in a grocery store with no support from onlookers, arguing that had the mother been White, the situation would never have happened. The fact that the woman in line looked at this mother and assumed she was 'illegal' seemed a clear example of racism. But others within the coding group argued that this experience was about legality and the power of immigration policy. While critical race theory informed the USA researcher, strong post-structural attention to power and privilege informed the French and Italian perspectives. The French member of our coding team argued that the insistence of the 
mother having a driver's license was a sociological matter of policy and power, not necessarily racism. He argued that given the strong backlash against illegal immigrants, immigrant parents are assumed illegal until proven otherwise. The German member of the coding team argued that immigrants are often silenced in such situations because of discrimination for a number of reasons including not only race but also language, cultural unfamiliarity and often poverty.

Making decisions about how to categorize people's personal experiences along with parent and teacher discourses is an interpretative act. This level of interpretation includes making decisions about voice and the power of research participants to speak and often entails a struggle with interpretations and perspectives. There was tension between the act of coding and our analytic frame. We ascribed to a Bakhtinian (Bakhtin and Holoquist 1981) literary analysis that focused not on multiple possible meanings of what parents and practitioners said in their interviews but also on how they borrow and use ideas from each other the larger societies in which they live and work. When we went to assign codes to these types of experiences and had to defend our choice of codes to one another, we struggled to agree on how Claudia's experience should be categorized and what labels we could assign similar experiences.

Claudia's experience in the grocery store not only pushed us to think about labels or codes but also about the level of interpretation our coding framework should have. Her story leads to a number of possible interpretations. Was her story primarily about racial discrimination or about policy? Was it about being a parent or being a woman? As a large research team, we were concerned with making sure the data could be organized and searched with the coding but also that the coding would support rather than take over the proposed analytical process.

After lengthy debates about how to code Claudia's experience in particular, we pulled back and tried to describe rather than interpret this mother's story. We agreed not to have a code for racism but to concentrate on a mechanism to find similar experiences in the data set. Deciding how much interpretation to do with the codes and coding frame is an important step because it determines part of the logic researchers will have to use to search the coding frame. For example, if we used the code 'racism' to label Claudia's experience and wanted to compare similar experiences of immigrant parents in different cities and countries it could be difficult because immigrant experiences could be categorized under a number of categories. As a team, we determined that because we were going to primarily be analysing the data through close interpretative readings, our priority was to make the data searchable and, thus, comparable. We created a code for stories of being in the new country, which in turn became the code 'migration stories'. We felt that this mother's stories and those like it were central pieces of data necessary to better understand the perspective of immigrant parents on their children's early schooling experiences. We made sure to have a code that covered immigration policy as well. Of course we realize that description is ane level an interpretation (Geertz 1973).

The debate over categorizing Claudia's experience also alerted us to the possibility of parents and teachers explicitly calling their experiences racist or describing acts or policies as racist. Because this was an important distinction in our research - when immigrant parents and teachers are specific in their 'race talk' (Pollack 2004) and when they are not, we settled on a code that could search for all of the comments where race is used or racist acts are named as 'racist'. We called this code 'discussions about race' and we included in the explanation of this code that the word race or racism had to be used in order for this code to apply. Claudia's experience was categorized with 
the code 'migration stories', not 'discussions about race' in order to see Claudia's experience not just singularly but also comparatively with immigrant parents throughout the five countries. We could then compare their stories with current research literature on the impact of immigration on parents' perspectives on education (see Valdes 1996; Ramirez 2003; Qin 2006) and ask comparative and timely questions impacting the field of education internationally. Do immigrant parents share common struggles even if they live in different countries? How do immigrant parents describe their own efforts to pass on cultural knowledge to their children while raising them in a foreign country?

As a project, we understood that ECEC programmes that serve children of immigrants, though well intentioned, often lack knowledge and consideration for parental perspectives, especially parents who are immigrants. We felt that in order to take seriously the voices of immigrant parents, we needed to see them collectively and be able to communicate their voices, as best we could, to the decision makers within ECEC programmes as well as other parents who could be empowered by hearing similar struggles to their own.

Coding is not only an organizational tool but a step towards analysis so creating it will most likely be complicated and somewhat time consuming (Miles and Huberman 1994). Even with efforts to balance etic/emic perspectives and decisions to resist higher levels of interpretation with coding, the coding process for large-scale, collaborative qualitative studies can be a site for passionate debates and disagreements about words, languages, theories and philosophies. By looking at segments of text and arguing about how to label them with codes, the CCB team had to address differences among the international research team and examine the power of language in developing the coding frame. For the remainder of this discussion we will focus on some of the debates over coding segments of text within the data set of immigrant parents and early childhood practitioners and why the project ultimately benefited from the coding framework process.

\section{Negotiating the coding framework development process}

One particular challenge for our team was the use of the word 'immigrant'. The problem of the word 'immigrant' had been with the CCB international team from the beginning stemming from the national differences in who is considered an immigrant. In the USA an immigrant is technically someone who was born out of the country and is not a citizen (2009). USA policy allows anyone born within the USA to be a citizen, so most of the children within the CCB study are not considered immigrant children but children of immigrants because $92 \%$ of children in preschool with immigrant parents were born in the USA. By contrast, Italy and Germany do not automatically give citizenship upon birth and so it is much more unclear when or at what generational stage someone stops being an im/migrant. Besides the political labeling, the lines between immigrant and nonimmigrant are much more blurry socially, even in the USA. Someone may have citizenship and be considered French or German but may also be referred to as immigrant even though their families have lived within the country for three or four generations. Because of negative labels for immigrants in the USA, particularly from Latin America, citizens of Latin descent still face discrimination and racial profiling (Santa Ana 2002)

Even in seemingly less controversial or politically charged topics like teaching practices, individual and/or national perspectives can be challenged while settling on 
code names. When we discussed how to capture the act of teaching in the coding framework, we debated a code name that could capture pedagogy or teaching. We struggled with coding teachers' ideas about teaching practices that involved accepted ideas about child development and developmental goals for children in early childhood settings, particularly children in im/migrant families. Some countries referred to this as pedagogy, some as teacher engagement. The US team described teachers in their focus groups as trying to help children develop self-esteem and autonomy. The Italian teachers' focus groups spoke about teachers as needing to give children a sense of belonging to a group or social competences in the group of peers. Behind the choice of these words it was possible to hear the echo of educational cultural traditions with some differences in their orientation and perception of the priorities for children's development and education. Within these discussions we traced different models of 'development of the self' - one more 'individual oriented' and one more 'inter-individual oriented' (Kagitcibasi 1996; Markus 1998).

Just like in the immigration examples, teachers approached the topic of teaching from many different angles. Sometimes they talked about their own approaches in the classroom about curriculum, dealing with different policies or managing discipline. As an example of teachers talking about teaching, here is a USA teacher talking about how she handles children using their home language at school:

We also do a lot of modeling for the kids that don't speak English. As far as, instead of like saying Spanish, I'm done, we'll say okay, you know, say, may I be excused. We do a lot of that modeling and word for word so they can start picking up that language. And I guess that's mostly what I'm doing in my classroom. (US teacher, in Farmville)

Here is a French teacher explaining their teaching in terms of structure and routine:

I admit that the small ones are almost deprived from playing because often they have finished their activity but I don't let them play right away, because the middle ones and the older ones are still working in their structured activities. (French teacher, Franqueville)

In these two examples, teaching is framed by personal practices in the classroom. But not all teachers framed their comments about teaching in this same way. Some teachers spoke about teaching in a more general sense such as what teachers should be doing in the classroom. This happened most often when teachers spoke specifically about teaching children of immigrants. Here, a German teacher who described teachers should do if they do not understand the home language of the children of immigrant families in their classrooms:

When can't speak the language oneself, there is also the possibility of getting help from people, parents or something, and there are like dual-language books. And when one doesn't speak the language oneself, then one could ask someone who can speak the language to read aloud or something. (German teacher, Loewenzahn)

Unlike the first two teachers from France and the USA, the German teacher offered possibilities for addressing certain concerns of teachers of children of immigrants. In this case her concern was not understanding the language of a child in her classroom. Still, the German teacher's possibilities were not framed as personal practice but more about what teachers should do. Teachers also spoke about their teaching practice in terms of relationships and interactions. In the Italian film that many of the teachers 
watched, the opening scene begins with a young boy and his mother with one of the teachers. The boy reluctantly says good-bye to his mother while the teacher tries to persuade him that it is time to enter the classroom. The boy keeps reminding his mother to make sure that his dad picks him and insists on a few more good-bye hugs and kisses. Eventually the little boy enters the class, goes to the window and exchanges a tearful wave with his mother. Gloomily, he walks to a teacher who is sitting down who reminds him that he loves school and he has already been at school for a while so it is time to stop crying. Most of the teachers who watched this scene, even in Italy, reacted to it by commenting on the interaction of the teacher, the parent and the child. In these cases, teachers' ideas about teaching were centred on the relationships and interactions with their teaching arenas. For example, during a focus group in Parma, Italy, teachers discussed this scene and talked about how as teachers they interact with children in their classrooms. They brought up that teachers should do as well as they do as teachers.

\begin{tabular}{|c|c|}
\hline hiara: & $\begin{array}{l}\text { regarding the activities, not so much on the activities something strike } \\
\text { me, they also said it, on the welcoming: the relationship with the } \\
\text { parents did not please me much. I mean, I felt it very cold, in contrast } \\
\text { with how you said (.) as we experience it. I also feel it personally, when } \\
\text { they arrive I feel like I want to exchange a chat, also when they leave: } \\
\text { greeting bevond the child even really the parent to exchange a word. }\end{array}$ \\
\hline Conductor: & $\begin{array}{l}\text { so in your opinion a time dedicated to this is a time well spent, from our } \\
\text { point of view; and that here is instead somewhat // }\end{array}$ \\
\hline Maria Teresa: & $\begin{array}{l}\text { I personally like it (.) it's something that I've always done, I cannot } \\
\text { always do it, but I also like to knee down to welcome the child, to really } \\
\text { feel at his/her level, when they arrive. ( ) Giving me a kiss, especially } \\
\text { if they are young (.) and I don't know, it comes natural to me. Because } \\
\text { it's less (.) I do it this way, personally // (Teachers in Poaletti 3) }\end{array}$ \\
\hline
\end{tabular}

The teachers here represent different ways of talking about teaching. These differences were complicated by various national cultures of teaching and learning present among the researchers creating the coding. We could not agree on how to divide teaching in a set of codes. The Italians argued that teachers could not separate their emotions and relationships from their teaching and that having a code about emotion or interaction that was different from practice was illogical. The act of kissing a child was a teaching practice, the same as making children wait to play until the older children were finished with their structured activity or modelling English phrases for children using their home language at school. The French argued that teaching practices are more philosophical, as a method of being positioned as the teacher in connection to how a teacher acts and thinks. The USA researcher tradition used the term pedagogy; the French used consigne (see Brougère, Guénif-Souilamas, and Rayna 2008). Arguing over categorization and how to divide the large topic of teaching practices into smaller codes forced us to look cross-nationally at the data. We had to look not only at how informants were talking about being a teacher but also about how national contexts of education talked about teachers and teaching. This conversation resulted in a need to attach and agree on coding definitions for each code. We knew that we could not find the perfect code to capture exact meanings. Instead we agree on specific definitions of words in the context of coding within our project.

Eventually we agreed upon a series of codes under the topical code of Preschool Practice including two that capture teachers' acts in the classroom: 
teacher engagement and teaching approach. We decided to distinguish between the affection and relationships of teachers and their instructional practices. To capture the multicultural and international ideas within 'teaching approach' as best we could, we agreed on the following definition of the code 'teaching approach': 'Pedagogy, consigne or instruction, self-esteem, self-expression of child, autonomy, encouragement, sense of belonging, how interact educationally with children in classroom. Comments about child/teacher centred, learning strategies, role of play versus work etc.' The definition of the teacher engagement code became, 'Affection, caring, touch, proximity, sensitivity and empathy'. These two definitions help us be able to search for instructional practices like the US, French and German teachers talking about how to respond to children of immigrant families in the classroom. And we could also search for more perspectives on how teachers should treat children of immigrant families in the classroom to compare to the Italian teachers' perspective about interacting with children when they arrive or are sad. This decision of course was not ideal, but still sensible, for the Italian philosophy of teaching and the natural logic they would have when searching the coding framework for teaching practices.

Developing coding frameworks not only lead to practical decisions like including definitions of codes and to compromises like in the case of categorizing teaching practices, but also to intense learning opportunities for those collaborating on the coding framework. Because we had to decide on codes or labels for transcripts, we realized the consequences of our own theoretical and national differences sooner in the analytical process. For an international and/or collaborative study, the ability to address different logics and ideas about education are critical to a comparative process. The coding framework process allowed for in-depth cross-national understanding of different educational systems. This began the international collaborative analysis and pushed other areas of analysis including close interpretative readings to address these same cultural and national differences in regards to early childhood education and care as well as more generalized teaching philosophies. These debates encouraged conversations about how different countries regulated immigration, whether second generation immigrants are still seen as immigrants or native-born formally or informally and about how ideas about cultural diversity within a society are represented in early childhood settings.

\section{Negotiating languages in the coding framework process}

Debating how to capture teaching and learning into codes is not only a matter of philosophy or national cultures of schooling. The use of English as the dominant language of the international coding framework structure included a series of compromises. In the French example of consigne, we struggled to find a suitable translation that would capture the depth of this pedagogical concept. Trying to trace this idea of a teacher's instruction and responsibility within the code 'teaching approach' necessitated using the word-concept of consigne in the code's definition as well as lengthy conversations about what is meant by consigne (see Brougère, Guénif-Souilamas, and Rayna 2008).

Designing the coding framework also entails attention to the languages used to code and the languages present in the data. In the CCB study issues with language emerged throughout the methodology. For the coding process in particular, there were focus groups in the dominant languages of French, German, English and Italian and many 
focus groups that were either conducted in the immigrant communities' language or simultaneously translated within the focus group for participants who struggled with the dominant language. English was chosen as the language for the coding framework but each transcript was coded in the original language of the transcript as well as English.

English as the dominant language was problematic within the CCB project as members of the research team had varying levels and experience with English. While this problem of interpretation was anticipated early on as an inevitable part of international comparative research, it was often frustrating during the coding process. Even though all of the researchers spoke English, the native speakers of French, Italian and German were forced to find imperfect translations of concepts or words. When multiple languages are present within any data set and researchers participating in the coding framework construction speak more than one language, it is important to be upfront about the limitations of English and/or any type of translation. The compromises that come from interpretation are etic constructions that again complicate efforts to have a coding framework that is meant to search and take seriously the voices of parents and practitioners in the research study.

Within our CCB timeline, researchers benefited from meeting together, designing the framework and then taking the framework back to our respective universities and research teams and trying it out on our data. We formulated questions that we wanted to ask the data and then tried to use the codes to find helpful data to address the topics raised within the questions. By doing this type of experimentation, we found holes in the framework and worked to include new codes or expand definitions. Codes that were being used differently or were not being used at all were identified and we could refine our definitions and clarify codes.

\section{Impact of the coding framework process}

Because the CCB project was primarily concerned with listening to the voices of immigrant parents and preschool teachers to understand their perspectives on early childhood education and care, the analytic process needed to remain close to the participants. In the end, the coding process allowed us to search for, hear and consider not just Claudia's story or Dahlia's but to hear them in connection to one another. And further, to hear them in relation to the societal and educational contexts in which they speak. In this article, we focused on Mercedes, Claudia and Dahlia as immigrant parents but they are also coded as mothers, women, Moroccan, Mexican, living in the USA, living in Italy. And they are coded in terms of what and how they talk about the education of their children.

The coding framework allowed researchers in the CCB project to trace these different aspects of the participants' voices within an ethnographically informed system of codes that remained close to the participants' voices as individuals and as multiple, collective groups with various meanings, connections and relationships (see Adair and Tobin 2007; Brougère, Guénif-Souilamas, and Rayna 2008; Arzubiaga and Adair 2009). Theoretically, this has meant a heightened attention to intersectionality (Crenshaw 1991) between and among participants because we can hear their experiences and perspectives in multiple ways, maintaining the richness of the original interviews. Practically, we can search the large amounts of data easier and faster to find and engage with the full range of participants instead of concentrating on a select few. 


\section{Conclusion}

Creating a coding framework to amplify the voices of marginalized groups within education is a process that encounters a series of challenges. Balancing emic and etic perspectives in the coding frame as well as making decisions about interpretation allows the resulting framework to be flexible enough for cultural meanings. There is no perfect framework that can reflect data exactly the way an individual researcher, let alone an international collaborative team, envisions it should be. So as part of the CCB team, we did not stop with just the coding process. We utilized other analytical processes like close interpretative readings to broaden our understanding and further check our coding process (see Tobin, Arzubiaga, and Mantovani 2007; Mantovani, Bove, and Tobin 2008; Kurban and Tobin 2009).

The coding process, in particular the design of a coding framework, can be a meaningful part of the research experience. The coding framework process can serve as an entryway into the data earlier and more deeply than might otherwise happen in a collaborative and/or large-scale project like CCB. Developing a coding framework is an opportunity to challenge culturally, nationally or professionally embedded ideas that researchers have about education and/or the topics brought up in their work. This additive coding process does categorize data and therefore limits how data can be searched on a large-scale. Instead of discouraging polyvocality, however, creating a coding framework with a balance of perspectives and a process of debates can actually produce a mechanism to foster research conversations about key educational topics and ultimately bring participants' experiences to light.

\section{Acknowledgements}

The authors wish to thank Joseph Tobin who coordinated and led the Children Crossing Borders study. The authors also wish to thank CCB colleagues Gilles Brougére, Annika Sulzer, Chris Pascal and Henriette Heimgaertner who worked collaboratively to develop the CCB coding framework.

\section{Notes}

1. Additional information on CCB including researcher biographies and national project findings can be found at www.childrencrossingborders.org

2. This is a synonym for a meat-processing company that owns and operates a factory in the town. The factory employs mostly immigrant parents and the majority of immigrant families have at least one parent working at the factory.

\section{References}

Adair, J.K., and J. Tobin. 2007. Listening to the voices of parents. In Diversities in early childhood education: Rethinking and doing, ed. C.G. Genishi and A.L. Goodwin, 137-50. New York: Routledge Falmer.

Arzubiaga, A., and J.K. Adair. 2009. Misrepresentations of language and culture, language and culture as proxies for marginalization: Debunking the arguments. In Handbook of Latinos and education, ed. E. Murillo, 301-8. New York: Routledge Falmer.

Auerbach, C.F., and L.B. Silverstein. 2003. Qualitative data: An introduction to coding and analysis. New York: New York University Press.

Bakhtin, M.M., and M. Holquist. 1981. The dialogic imagination: Four essays. Austin, TX: University of Texas Press.

Bakhtin, M. M., M. Holquist, and V. Liapunov. 1990. Art and answerability: Early philosophical essays. 1st ed. Austin, TX: University of Texas Press. 
Brougère, G., N. Guénif-Souilamas, and S. Rayna. 2008. Ecole maternelle (preschool) in France: A cross-cultural perspective. European Early Childhood Education Research Journal 16, no. 3: 371-84.

Crenshaw, K.W. 1991. Mapping the margins: Intersectionality, identity politics, and violence against women of color. Stanford Law Review 43, no. 6: 1241-99.

Erickson, P., and L. Murphy. 2008. A history of anthropological theory. Toronto: University of Toronto Press.

Geertz, C. 1973. The interpretation of cultures. New York: Basic Books.

Harkness, S., U. Moscardino, M.R. Bermùdez, P.O. Zylicz, B. Welles-Nystrom, M. Blom, P. Parmar, G. Axia, J. Palacios, and C. Super. 2006. Mixed methods in international collaborative research: The experiences of the international study of parents, children and schools. Cross Cultural Research 40, no. 3: 67-82.

Headland, T., K. Pike, and M. Harris, eds. 1990. Emics and etics: The insider/outsider debate. Newbury Park, CA: Sage.

Kagitcibasi, C. 1996. Family and human development across cultures: A view from the other side. Hillsdale, NJ: Lawrence Erlbaum.

Kurban, F., and J. Tobin. 2009. 'They don't like us': Reflections of Turkish children in a German preschool. Contemporary Issues in Early Childhood Education 10, no. 1: 24-34.

Mantovani, S., C. Bove, and J. Tobin. 2008. Methodological issues in video-based research on immigrant children and parents in ECEC. In New Frontiers of Phenomenology: Proceeding of the International Human Research Conference, ed. M. Tarozzi and R. Bertolani. Rovereto, Italy: Università degli studi di Trento.

Markus, K. 1998. The cultural psychology of personality. Journal of Cross-Cultural Psychology 29: 63-87.

Miles, M.B., and A.M. Huberman. 1994. Qualitative data analysis. 2nd ed. Thousand Oaks, CA: Sage.

Pollack, M. 2004. Colormute: Race talk dilemmas in an American school. Princeton, NJ: Princeton University Press.

Qin, D.B. 2006. 'Our child doesn't talk to us anymore': Alienation in immigrant Chinese families. Anthropology and Education Quarterly 37, no. 2: 162-79.

Ramirez, A.Y.F. 2003. Dismay and disappointment: Parental involvement of Latino immigrant parents. Urban Review 35, no. 2: 93-110.

Santa Ana, O. 2002. Brown tide rising: Metaphors of Latinos in contemporary American public discourse. Austin, TX: University of Texas Press.

Strauss, A.L., and J. Corbin. 1998. Basics of qualitative research: Grounded theory procedures and techniques. Newbury Park, CA: Sage.

Tobin, J. 2000. Good guys don't wear hats: Children's talk about the media. New York: Teachers College Press.

Tobin, J., A. Arzubiaga, and S. Mantovani. 2007. Entering dialogue with immigrant parents. Early childhood matters. The Hague: Bernard Van Leer Foundation.

Tobin, J., Y. Hsueh, and M. Karasawa. 2009. Preschool in three cultures revisited. Chicago, IL: University of Chicago Press.

Tobin, J., D.Y.H. Wu, and D.H. Davidson. 1989. Preschool in three cultures: Japan, China, and the United States. New Haven, CT: Yale University Press.

Valdes, G. 1996. Con respeto: Bridging the distances between culturally diverse families and schools - An ethnographic portrait. New York: Teachers College Press. 